\title{
The Use of Alkaline Hydrolysis As a Novel Strategy for Chloroform Remediation: The Feasibility of Using Construction Wastes and Evaluation of Carbon Isotopic Fractionation
}

\author{
Clara Torrentó, ${ }^{* \dagger}$ Carme Audí-Miró, ${ }^{\dagger}$ Geneviève Bordeleau, ${ }^{\ddagger}$ Massimo Marchesi ${ }^{\dagger, \S}$ Mònica Rosell, ${ }^{\dagger}$ \\ Neus Otero, ${ }^{\dagger}$ and Albert Soler ${ }^{\dagger}$ \\ ${ }^{\dagger}$ Grup de Mineralogia Aplicada i Medi Ambient, Departament de Cristal-lografia, Mineralogia i Dipòsits Minerals, Facultat de \\ Geologia, Universitat de Barcelona (UB), Martí Franquès s/n, 08028. Barcelona, Spain \\ ${ }^{\ddagger}$ National Scientific Research Institute (INRS-ETE), 490 de la Couronne, G1K 9A9 Quebec, Quebec, Canada \\ ${ }^{\S}$ Department of Earth \& Environmental Sciences, University of Waterloo, 200 University Ave. W, N2L 3G1 Waterloo, Ontario, \\ Canada
}

Supporting Information

ABSTRACT: Laboratory and field-scale pilot experiments were performed to evaluate the feasibility of chloroform degradation by alkaline hydrolysis and the potential of $\delta^{13} \mathrm{C}$ values to assess this induced reaction process at contaminated sites. In batch experiments, alkaline conditions were induced by adding crushed concrete $(\mathrm{pH} 12.33 \pm 0.07)$, a filtered concrete solution $(\mathrm{pH} 12.27 \pm 0.04)$, a filtered cement solution $(\mathrm{pH} 12.66 \pm 0.02)$ and a $\mathrm{pH} 12$ buffer solution $(\mathrm{pH} 11.92 \pm 0.11)$. The resulting chloroform degradation after 28 days was 94, 96, 99, and $72 \%$, respectively. The experimental data were described using a pseudo-first-order kinetic model, resulting in pseudo-first-order rate constant values of 0.10 , $0.12,0.20$, and $0.05 \mathrm{~d}^{-1}$, respectively. Furthermore, the significant chloroform carbon isotopic fractionation associated with alkaline

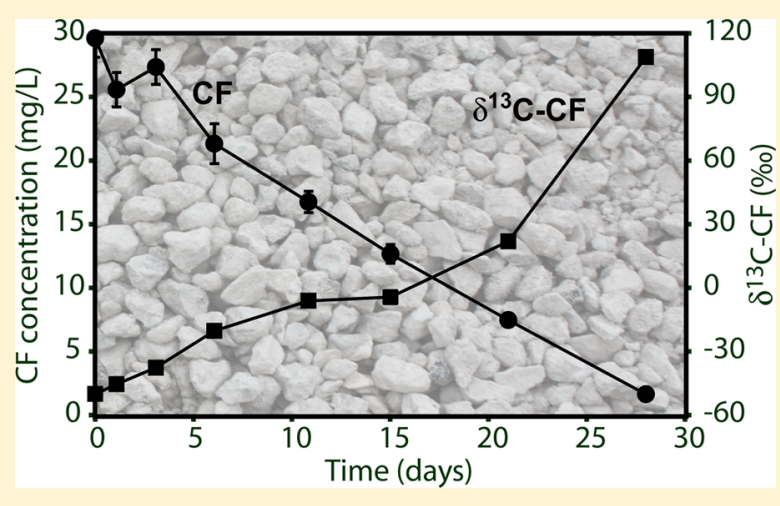
hydrolysis of chloroform $(-53 \pm 3 \%$ ) and its independence from $\mathrm{pH}$ in the admittedly limited tested $\mathrm{pH}$ range imply a great potential for the use of $\delta^{13} \mathrm{C}$ values for in situ monitoring of the efficacy of remediation approaches based on alkaline hydrolysis. The carbon isotopic fractionation obtained at the lab scale allowed the calculation of the percentage of chloroform degradation in field-scale pilot experiments where alkaline conditions were induced in two recharge water interception trenches filled with concrete-based construction wastes. A maximum of approximately $30-40 \%$ of chloroform degradation was achieved during the two studied recharge periods. Although further research is required, the treatment of chloroform in groundwater through the use of concrete-based construction wastes is proposed. This strategy would also imply the recycling of construction and demolition wastes for use in value-added applications to increase economic and environmental benefits.

\section{INTRODUCTION}

Halogenated volatile organic compounds are some of the most prevalent contaminants in groundwater. ${ }^{1}$ Chloroform (CF) is one of the highest ranked halogenated volatile organic compounds on the Agency for Toxic Substances and Disease Registry (ATSDR) priority list of hazardous substances. This list compiles the compounds found at sites on the National Priorities List (NPL) in the United States that pose the most significant potential threat to human health. ${ }^{2}$ In Europe, an environmental quality standard of $2.5 \mu \mathrm{g} / \mathrm{L}$ for CF has been established in the framework of water policy (Directive 2008/ 105/EC).

$\mathrm{CF}$ aerobic and anaerobic microbial cometabolic processes have been described. ${ }^{4}$ However, apart from recent reports describing $\mathrm{CF}$ as a terminal electron acceptor during growth of Dehalobacter-containing cultures, ${ }^{5,6}$ CF cometabolic degrada- tion is restricted by several environmental factors (inhibition by the presence of growth substrates such as other chlorinated compounds, toxicity of derived metabolites, etc.). ${ }^{4}$ Bioremediation of $\mathrm{CF}$ by biostimulation and/or bioaugmentation strategies has been suggested. ${ }^{3,7}$ Nevertheless, to our knowledge, in situ bioremediation of these compounds has not been reported to date. Furthermore, although removal of many halogenated hydrocarbons from groundwater can be achieved by in situ chemical oxidation (ISCO), CF is poorly reactive with common oxidants, such as permanganate, iron-activated persulfate, ozone, hydrogen peroxide, or Fenton's Reagent. ${ }^{8}$

Received: August 29, 2013

Revised: January 3, 2014

Accepted: January 10, 2014

Published: January 10, 2014 
New remediation strategies, that are efficient for this recalcitrant compound, should therefore be developed. Alkaline hydrolysis has been proposed as a remediation technology for other types of contaminants, such as explosives, ${ }^{9-13}$ organophosphorous insecticides, ${ }^{14}$ tert-butyl formate, ${ }^{15}$ and $1,2,3-$ trichloropropane. ${ }^{16}$ To our knowledge the Bondgaard et al. ${ }^{17}$ study is the only pilot-scale experiment for in situ alkaline hydrolysis-based groundwater remediation implemented in a contaminated site until now. However, alkaline hydrolysis has received little attention so far with respect to chlorinated methanes. In general terms, hydrolysis is a reaction in which an organic molecule reacts with a water molecule (or hydroxide ion) and one part of the organic molecule (i.e., the leaving group) is split off from the molecule. ${ }^{18}$ In the halogenated hydrocarbons, the leaving group is a halide ion, and hydrolysis of these compounds includes both nucleophilic substitution and elimination reaction mechanisms. The competition between elimination and nucleophilic substitution reactions depends on the structure of the substrate, the nature of the base and stereoelectronic factors. Because strong nucleophiles favor elimination over nucleophilic substitution, alkaline hydrolysis reactions (i.e., reaction with $\mathrm{OH}^{-}$) of polyhalogenated aliphatic compounds are expected to be dominated by elimination reactions, whereas neutral hydrolysis (i.e., reaction with $\mathrm{H}_{2} \mathrm{O}$ ) is expected to occur primary by nucleophilic substitution reactions. ${ }^{19}$ The $\mathrm{pH}$ at which the changeover from the dominance of neutral reactions to the dominance of alkaline reactions occurs, $\mathrm{I}_{\mathrm{NB}}$, is different for each compound, being 6.5 in the case of $\mathrm{CF}^{18}$

Hydrolysis of chlorinated compounds has been well demonstrated in the literature. ${ }^{20-24}$ However, reaction rates are often quite slow within the range of normal groundwater temperatures and $\mathrm{pH}$ values. For this reason, reported rates of hydrolysis reactions involving chlorinated solvents are typically the result of extrapolation from experiments performed at higher temperatures. Neutral hydrolysis of $\mathrm{CF}$ is very slow, with reported neutral first-order rate constants $\left(K_{\mathrm{N}}\right)$ at $25{ }^{\circ} \mathrm{C}$ and $\mathrm{pH} 7$ ranging from $6.2 \times 10^{-8}$ (extrapolated from Fells and Moelwyn-Hughes ${ }^{25}$ ) to $2.8 \times 10^{-7}$ day $^{-1}$, which would translate into half-lives of approximately 30700 and 6900 years, respectively. Because $\mathrm{OH}^{-}$cannot compete successfully with water in substitution reactions with simple halogenated hydrocarbons at typical ambient conditions, the neutral hydrolysis reaction may be described by a first-order law, regardless of whether the reaction occurs by an $\mathrm{SN}_{1}$ or $\mathrm{SN}_{2}$ substitution mechanism or a mixture of both. Neutral hydrolysis of $\mathrm{CF}$ is therefore first-order with respect to the concentration of $\mathrm{CF}$ and is independent of $\mathrm{pH}^{22}$ Regarding the alkaline hydrolysis of CF in an aqueous solution, experimental and theoretical approaches suggested that it proceeds through an $\mathrm{E} 1_{\mathrm{CB}}$ mechanism and that the $\mathrm{SN}_{2}$ mechanism is unlikely to play a major role. ${ }^{20,26}$ The $E 1_{\mathrm{CB}}$ mechanism is a type of elimination reaction, which, in general terms, consists of a first step where a $\mathrm{C}-\mathrm{H}$ bond is broken by deprotonation with a base, followed by a second step where the leaving group is expelled. In the case of $\mathrm{CF}$, the $\mathrm{E} 1_{\mathrm{CB}}$ mechanism features the rapid, reversible, base-catalyzed deprotonation of the molecule with the formation of trichloromethyl carbanion $\left(\mathrm{CCl}_{3}^{-}\right)$, followed by the rate-determining unimolecular loss of a chloride ion to produce the reactive intermediate carbon dichloride, which is then rapidly transformed into the final products, carbon monoxide and formate ion.

$$
\begin{aligned}
& \mathrm{CHCl}_{3}+\mathrm{OH}^{-} \stackrel{\text { fast }}{\longleftrightarrow} \mathrm{CCl}_{3}^{-}+\mathrm{H}_{2} \mathrm{O} \\
& \mathrm{CCl}_{3} \stackrel{\text { slow }}{\longrightarrow} \mathrm{CCl}_{2}+\mathrm{Cl}^{-} \\
& \mathrm{CCl}_{2} \stackrel{\mathrm{OH}^{-} \mathrm{H}_{2} \mathrm{O}}{\longrightarrow} \mathrm{CO}+\mathrm{HCO}_{2}^{-}
\end{aligned}
$$

The rate of the reaction has been suggested to be first order with respect to both $\mathrm{OH}^{-}$and $\mathrm{CF}$ concentrations. ${ }^{20,25}$ Following this assumption and using the neutral and alkaline rate constants $\left(k_{\mathrm{N}}\right.$ and $k_{\mathrm{B}}$, respectively) of the hydrolysis of $\mathrm{CF}$ at $25{ }^{\circ} \mathrm{C}$ reported by Jeffers et al. ${ }^{22}\left(k_{\mathrm{N}}=2.8 \times 10^{-7} \mathrm{~d}^{-1} ; k_{\mathrm{B}}=\right.$ $\left.7.5 \mathrm{M}^{-1} \mathrm{~d}^{-1}\right)$ and extrapolated from Fells and MoelwynHughes $^{25}\left(k_{\mathrm{N}}=6.2 \times 10^{-8} \mathrm{~d}^{-1} ; k_{\mathrm{B}}=5.7 \mathrm{M}^{-1} \mathrm{~d}^{-1}\right)$, pseudofirst-order rate constant $\left(k_{\text {obs }}^{\prime}=\mathrm{k}_{\mathrm{N}}+k_{\mathrm{B}} \mathrm{C}_{\mathrm{OH}-}\right)$ values of 0.075 and $0.057 \mathrm{day}^{-1}$, respectively, can be calculated at constant $\mathrm{pH}$ 12 (Table 1 ). This yields half-lives of approximately 9-12 days,

Table 1. Summary of the Kinetics of CF Degradation by Hydrolysis under Alkaline Conditions ${ }^{a}$

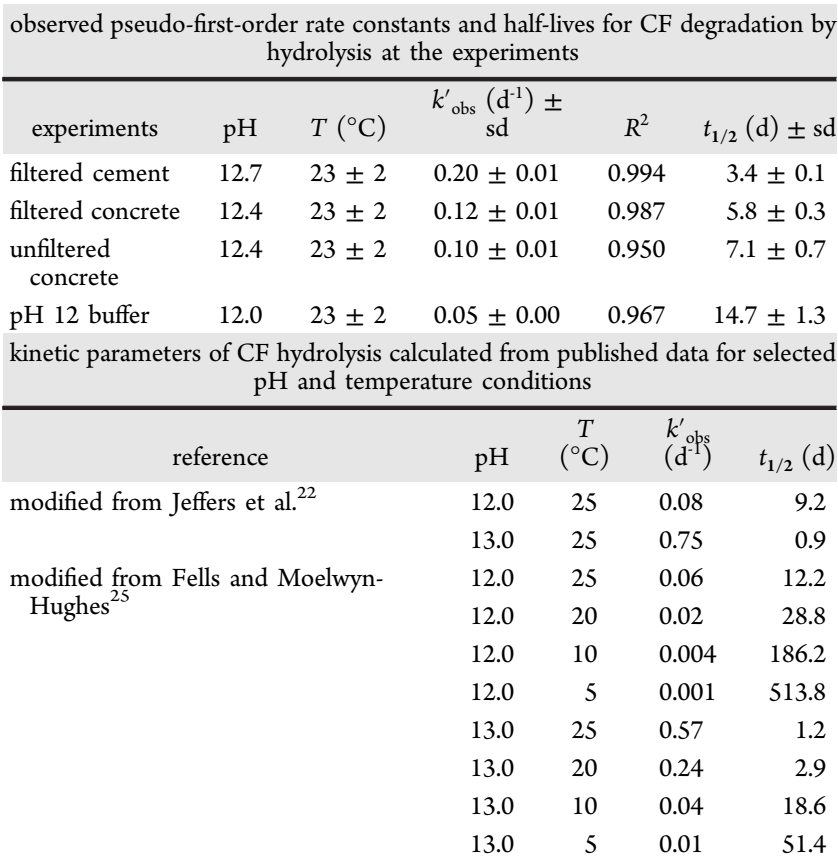

${ }^{a}$ Pseudo-first-order rate constant $\left(\mathrm{k}^{\prime}{ }_{\mathrm{obs}}\right)$ errors are given as the standard deviation ( $\mathrm{sd}$ ) calculated on the regression of the pseudofirst-order kinetic model. Half-life $\left(t_{1 / 2}\right)$ uncertainties were calculated by propagation of the first-order rate constant errors. Pseudo-firstorder rate constants and half-lives calculated from the published data of Jeffers et al. ${ }^{22}$ and Fells and Moelwyn- Hughes ${ }^{25}$ for $\mathrm{pH}$ values of 12 and 13 and for temperatures $(T)$ of $5,10,20$, and $25{ }^{\circ} \mathrm{C}$ are also shown. The empirical temperature dependence relationships reported by Fells and Moelwyn- Hughes ${ }^{25}$ (SI Equations 12 and 13) were used to extrapolate rate constants to the selected temperatures.

which implies an attractive potential use of CF remediation strategies based on alkaline hydrolysis. All the literature cited above determined the kinetics of CF hydrolysis in homogeneous solutions. In contrast, the effects of heterogeneity on the hydrolysis rates have received little attention so far. ${ }^{27}$ Amonette et al. $^{27}$ studied the effect of various mineral phases (montmorillonite, kaolinite, albite, and muscovite) on the hydrolysis rates of CF. The authors observed a significant effect of the type of solid on the CF hydrolysis rates at $50{ }^{\circ} \mathrm{C}$, which 
was attributed to the different $\mathrm{pH}$ values maintained by the solid phases in contact with the aqueous phase.

In the present study, we propose that concrete might be used to maintain alkaline conditions and thus to induce alkaline hydrolysis of CF. Concrete is an artificial conglomerate stone made essentially of Portland cement, aggregates, water and supplementary cementitious materials. Portland cement is made by heating finely ground limestone and finely divided clay at high temperatures. Concrete has high $\mathrm{pH}$ buffering capacity due to the lime content of the cement. For these reasons, recycled concrete has been used as a reactive material for neutralizing acidic groundwater. ${ }^{28-30}$ Furthermore, cementbased stabilization/solidification $(\mathrm{s} / \mathrm{s})$ treatments have been proven to immobilize chlorinated solvents from contaminated soils and groundwater. ${ }^{31-33}$ These $\mathrm{s} / \mathrm{s}$ treatments have been used in combination with abiotic reductive dechlorination treatments with additions of $\mathrm{Fe}(\mathrm{II})$, in which ferrous iron and cement are used as an electron donor and a catalyst, respectively. The feasibility of the use of concrete to induce alkaline hydrolysis and/or sorption of CF at contaminated sites merits evaluation.

To assess the efficiency of remediation strategies at contaminated sites, the interpretation of concentration data alone is often insufficient; therefore, isotopic data are required. For example, the presence of a contaminant downgradient of a permeable reactive barrier (PRB) may result from incomplete degradation within the PRB, from bypassing under or around the PRB or from contaminants already present before the installation of the PRB. To distinguish these origins, compound specific isotope analysis (CSIA) can be used. The fundamentals of this approach imply that biological and chemical degradation reactions, which involve the cleavage of chemical bonds, usually cause isotopic fractionation. The result is generally an enrichment in heavy isotopes in the remaining substrate because light isotopomers (e.g., ${ }^{12} \mathrm{C},{ }^{1} \mathrm{H}$ and ${ }^{35} \mathrm{Cl}$ ) typically react faster than heavy isotopomers (e.g., ${ }^{13} \mathrm{C},{ }^{2} \mathrm{H}$ and $\left.{ }^{37} \mathrm{Cl}\right) .{ }^{34}$ In contrast, nondestructive abiotic natural processes, such as dispersion, sorption or volatilization, generally do not cause significant isotopic fractionation. ${ }^{35-39}$ Therefore, significant changes in isotope ratios over time and space can be used to monitor the success of remediation strategies at contaminated sites. $^{30}$ Quantification of the extent of contaminant transformation based on stable isotopes requires the experimental determination of the isotopic fractionation associated with the reaction under consideration.

In this study, laboratory batch experiments and field-scale pilot experiments were performed. The batch experiments were carried out to investigate the capacity of concrete to induce alkaline hydrolysis of CF. Additionally, the field-scale pilot experiments were performed to evaluate the feasibility of inducing alkaline hydrolysis of CF in the recharge water of a highly polluted fractured bedrock aquifer by implementing two interception trenches filled with construction wastes (recycled concrete aggregates). The main objectives of this study were (i) to evaluate, through the batch experiments, $\mathrm{CF}$ consumption under alkaline conditions ( $\mathrm{pH} 12.0-12.7)$ induced by a solution with crushed concrete, a filtered concrete solution, a filtered cement solution and a $\mathrm{pH}$ buffer solution; (ii) to use carbon isotopic tools to determine whether fractionation occurs in both batch and field experiments in order to discriminate if a reduction in concentration is produced due to degradation or to nontransformation processes; and (iii) to determine if the magnitude of the lab-obtained carbon isotopic fractionation is high enough to assess and quantify the induced alkaline hydrolysis of $\mathrm{CF}$, first, at the pilot field experiment and, later, at contaminated field sites. Because tetrachloromethane (CT), commonly found together with $\mathrm{CF}$, is considered a recalcitrant compound listed on the ATSDR priority list as well, additional laboratory batch experiments and field-scale pilot experiments were also conducted to assess the behavior of CT under induced alkaline conditions. Concentration and isotope results and a discussion about CT are found in the Supporting Information (SI).

\section{MATERIALS AND METHODS}

2.1. Laboratory-Scale Experiments. Batch experiments were performed to assess the induced alkaline hydrolysis of CF and to determine the magnitude of carbon isotopic fractionation associated with this process. The materials and solutions used in the experiments are detailed in the SI. Alkaline conditions were induced by adding concrete particles (achieving a $\mathrm{pH}$ value of $12.37 \pm 0.03$ ) or by using the three different alkaline solutions described in the SI. The experiments with the filtered concrete solution and with the concrete particles were performed to distinguish the effects of degradation versus sorption. Glass vials $(26 \mathrm{~mL})$ were used as reaction vessels for the filtered concrete, filtered cement, chemical buffer, and control experiments. These vials were filled with the corresponding alkaline solutions or, in the case of the control experiments, with distilled water ( $\mathrm{pH} 5.5 \pm 0.2)$. For the experiments with concrete particles, $39 \mathrm{~mL}$ glass vials were filled with $20 \mathrm{~g}$ of crushed concrete and approximately $30 \mathrm{~mL}$ of distilled water. In all vials, the reaction was started by adding an appropriate volume of the contaminant stock solution described in the SI to provide an initial CF concentration of 30 $\mathrm{mg} \mathrm{L}^{-1}$. The vials were completely filled without any headspace to avoid partitioning of chlorinated compounds between the aqueous and gas phases and were closed with PTFE-lined caps. Furthermore, the vials were covered with aluminum foil to avoid photochemical effects. Duplicates (labeled A and B) were performed and all the experiments were conducted at a room temperature of $23 \pm 2{ }^{\circ} \mathrm{C}$. The experiments were started at different times to achieve reaction times varying from 0 to 28 days. After 28 days from the earliest prepared vials, all the vials were sacrificed at the same time, ensuring that from the stop of the reactions until the analyses, which would be on the same day for all the reactors, all the samples underwent the same storage conditions. Appropriate volumes of the $\mathrm{pH} 6$ buffer solution were added to the vials to neutralize the solution to $\mathrm{pH}$ 6 and quench the alkaline hydrolysis reaction (i.e., $2.1 \mathrm{~mL}$ for the $26 \mathrm{~mL}$ vials). Preliminary experiments proved that no catalyst effect was induced by the added quenching solution (data not shown). In the experiments with concrete particles, the particles were discarded and the solution was filtered with a $0.45 \mu \mathrm{m}$ syringe nylon filter (Uptidisc $25 \mathrm{~mm}$, Interchim, France) before neutralization. Samples were held at $4{ }^{\circ} \mathrm{C}$ in darkness until analysis (within one week).

2.2. Field-Scale Pilot Experiments. Two field-scale pilot interception trenches were installed in the unsaturated zone of a contaminated fractured bedrock aquifer to induce alkaline hydrolysis of $\mathrm{CF}$ in the contaminated recharge water accumulated in the trenches before the water reaches the aquifer. The aquifer is unconfined fractured bedrock, consisting mainly of an Eocene blue-gray limestone bed, which forms a low-permeability matrix with conductive fractures and fissures. ${ }^{40}$ The aquifer is mainly contaminated by chlorinated 
ethenes, ethanes, methanes, and chlorobenzenes, together with traces of BTEX and pesticides. An underground wastewater tank and a disposal pit located outside of the factory building were identified as the main contaminant release sources. High volatile organic compounds concentrations were detected in the subsurface in the areas located around the main pollution sources (SI Figure S1). The main measures implemented for the mitigation of the contamination, performed in July 2006, were the removal of approximately $2000 \mathrm{t}$ of contaminated soil in the vicinity of the pollution source areas and the installation of the two interception trenches in the unsaturated zone where contaminated soil had been removed (pit trench and tank trench). The pit trench is $14 \mathrm{~m}$ long, $6 \mathrm{~m}$ wide and $6.5 \mathrm{~m}$ deep, whereas the tank trench is $28 \mathrm{~m}$ long, $6 \mathrm{~m}$ wide and $6.5 \mathrm{~m}$ deep (SI Figure S2). The trenches were filled with $40-70 \mathrm{~mm}$-sized recycled concrete-based aggregates from a construction and demolition waste recycling plant. These aggregates had a density of approximately $1.10 \mathrm{t} \mathrm{m}^{-3}$. Finally, at $50 \mathrm{~cm}$ below the ground surface, a geotextile sheet was placed, which was covered by a layer of compacted clays. Three and five monitoring wells were installed along the pit and tank trenches, respectively (SI Figure S2). Rainwater lixiviates contaminants retained in the unsaturated zone and infiltrates to the trenches, where CF alkaline hydrolysis can be induced. Trench water discharges to the unsaturated zone toward the SSE, following the main water flow direction until reaching a fracture connected to the underlying carbonate aquifer (SI Figure S3). The trenches discharge until a minimum level, and the water accumulated in both trenches is occasionally removed for its management.

Sampling of the water accumulated in the trenches through one of the monitoring wells of each trench was performed monthly from June 2010 until April 2013. This periodical sampling started 15 days after the trenches were emptied. The collected data are divided into two different periods, henceforth called the first (9 months, from June 12th 2010 to February 23rd 2011) and the second (26 months, March 21st 2011 to April 29th 2013) recharge periods, following water removals on May 26th 2010 and February 23rd 2011, respectively. Physicochemical parameters $(\mathrm{pH}$, temperature, conductivity, Eh, and dissolved oxygen) were measured in situ using a flowthrough cell (Eijkelkamp, Netherlands) to avoid contact with the atmosphere. Additional details are provided in the SI. Water samples for concentration measurements and isotopic analyses of chlorinated volatile organic compounds were collected in $125 \mathrm{~mL}$ amber glass bottles, completely filled and closed with PTFE-lined caps. Samples were held at $4{ }^{\circ} \mathrm{C}$ in darkness until analysis. The water level in the trenches and groundwater level in two wells downgradient from both trenches were continuously recorded using Cera- and Mini-Divers (Schlumberger Water Service, Postbus, Netherlands), respectively.

2.3. Analytical Methods. Chlorinated compound concentrations were determined by headspace (HS) analysis using a FOCUS gas chromatograph coupled with a DSQ II mass spectrometer (Thermo Fisher Scientific, Waltham, MA). Concentrations in the batch experiments were corrected for the dilution induced by the addition of the quenching solution. Carbon isotope analyses of chlorinated compounds were performed using a Thermo Finnigan Trace GC Ultra instrument coupled via a GC-Isolink interface to a Delta V Advantage isotope ratio mass spectrometer (Thermo Scientific $\mathrm{GmbH}$, Bremen, Germany). Additional details are provided in the SI.
Aliquots of samples were preserved in nitric acid to measure concentrations of cations by inductively coupled plasma-optical emission spectrometry (ICP-OES) and inductively coupled plasma mass spectrometry (ICP-MS). Dissolved chloride concentration was measured in duplicate by titration with a $\mathrm{AgNO}_{3} 0.0125 \mathrm{~N}$ solution using a $702 \mathrm{SM}$ Titrino automatic titrator. The error based on replicate measurements was 5\%. Solution $\mathrm{pH}$ was measured with a calibrated WTW $\mathrm{pH}$ Meter at room temperature $\left(23 \pm 2{ }^{\circ} \mathrm{C}\right)$. The $\mathrm{pH}$ error was $0.02 \mathrm{pH}$ units. Alkalinity (as $\mathrm{HCO}_{3}^{-}$) was analyzed by automatic titration using unfiltered samples.

\section{RESULTS}

3.1. Laboratory Experiments. Consumption of CF was observed over time in all the experiments, except in the controls, in which concentrations remained unchanged up to 28 days (Figure 1A) and chloride formation was not detected
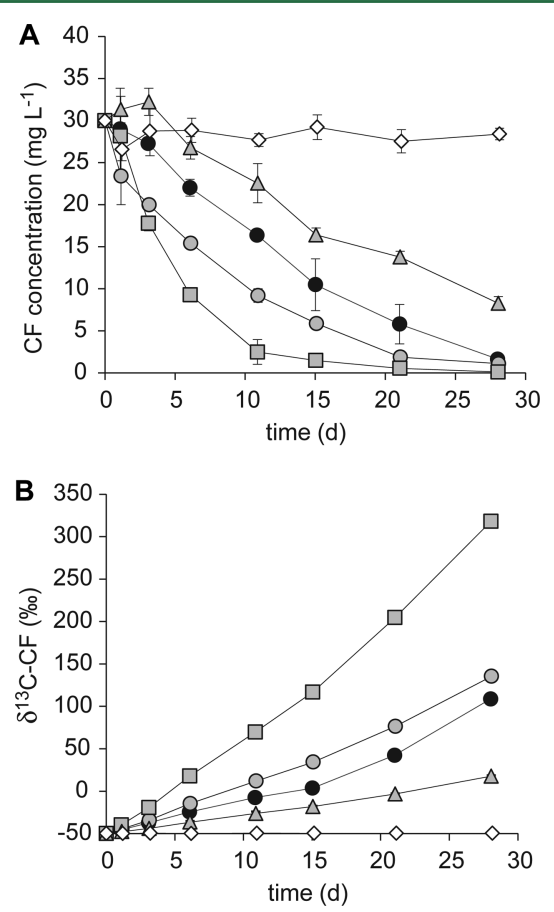

Figure 1. Changes in the concentration (A) and $\delta^{13} \mathrm{C}$ values (B) of CF over time in the alkaline hydrolysis laboratory experiments: unfiltered concrete experiments (black circles), filtered concrete experiments (gray circles), filtered cement experiments (squares), buffer experiments (triangles), and control experiments (diamonds). The error bars show the standard deviation for duplicate experiments.

(data not shown). The results of the control experiments rule out possible losses of CF as a result of processes not induced by alkaline conditions. Under alkaline conditions, contaminant degradation ranged from $72 \%$ (buffer experiments) to $99 \%$ (filtered cement experiments) after 28 days (Figure 1A). In each treatment, the $\mathrm{pH}$ remained constant over the duration of the experiments $(12.33 \pm 0.07$ in the concrete experiments, $12.27 \pm 0.04$ in the filtered concrete experiments, $12.66 \pm 0.02$ in the filtered cement experiments and $11.92 \pm 0.11$ in the buffer experiments). The hydrolysis of CF under alkaline conditions followed pseudo-first-order kinetics, as evidenced by the linear correlation relationship in $\ln \left(\mathrm{C} / \mathrm{C}_{0}\right)$ vs time graphs (SI Figure S4). Least-squares regression analysis showed $R^{2}>$ 0.95 (Table 1). The rate of CF degradation generally increased 
as the $\mathrm{pH}$ of the alkaline solutions increased, with pseudo-firstorder rate constant values, $\mathrm{k}_{\text {obs }}^{\prime}$, ranging from 0.047 to 0.201 $\mathrm{d}^{-1}$. For all tested alkaline $\mathrm{pH}$ values, the half-life was less than 15 days (Table 1). The obtained second-order rate constant was $4.6 \pm 2.4$ (95\% confidence interval) $\mathrm{M}^{-1} \mathrm{~d}^{-1}$ (see SI for calculation details and Figure S5). The order of the reaction was obtained as the slope of the same logarithm plot, and was $1.1 \pm 0.5$. Hydroxide concentrations were not directly measured but were estimated from $\mathrm{pH}$ values and ionic strength data using the code PHREEQC and the thermodynamic database MINTEQ.v4. ${ }^{41}$

The initial concrete and cement solutions contained 2.1 and $15.8 \mathrm{mg} \mathrm{L}^{-1}$ of chloride, respectively. The chloride concentration related to $\mathrm{CF}$ dechlorination at each sampling time was determined by subtracting the background concentrations (measured in the initial concrete and cement solutions) from the measured dissolved chloride concentrations in the samples. The total molar mass balance of chlorine (chloride released + chlorine in the remaining $\mathrm{CF}$ ) at each sampling time ranged from 81 to $127 \%, 91$ to $105 \%$, and 92 to $112 \%$ of the initial chlorine mass throughout the experiments with concrete particles, filtered concrete solution, and filtered cement solution, respectively (SI Figure S6). In addition to chloride, the experiments with concrete particles released $\mathrm{Ca}, \mathrm{K}, \mathrm{S}, \mathrm{Sr}$, $\mathrm{Ba}, \mathrm{Li}, \mathrm{Al}$, and $\mathrm{Zn}$ into solution, with concentrations after 28 days of approximately $240,80,6.0,1.5,1.0,0.15,0.1$, and 0.05 $\mathrm{mg} \mathrm{L}^{-1}$, respectively (SI Table $\mathrm{S} 1$ ). Other measured cations ( $\mathrm{Cd}, \mathrm{As}, \mathrm{Cu}, \mathrm{Ni}, \mathrm{Pb}, \mathrm{Cr}, \mathrm{Hg}, \mathrm{Fe}$, and $\mathrm{Mg}$ ) were below detection limits.

All of the CF experiments, except the control experiments, show a considerable enrichment in ${ }^{13} \mathrm{C}$ in the remaining $\mathrm{CF}$ over the course of the experiments (Figure 1B). Carbon isotopic fractionations $\left(\varepsilon_{\mathrm{C}}\right)$ were evaluated by a linear regression of the data following the Rayleigh equation (more details are shown in the SI). The resulting plots can be found in the SI (Figure S7), and the experimental results are summarized in Table 2. Good fits (i.e., $R^{2}>0.96$ ) were

Table 2. Carbon Isotope Fractionation $\left(\varepsilon_{\mathrm{C}}\right)$ and $\mathbf{9 5 \%}$ Confidence Interval (95\% CI) of the Regression Lines for Hydrolysis of CF under the Alkaline Conditions Reported for the Experiments, As Well As Total Combined Data

\begin{tabular}{lcrc}
\multicolumn{1}{c}{ experiments } & $\varepsilon_{\mathrm{C}}(\% 0) \pm 95 \%$ CI & \multicolumn{1}{c}{$n^{a}$} & $R^{2}$ \\
filtered cement & $-56 \pm 10$ & 8 & 0.968 \\
filtered concrete & $-53 \pm 5$ & 11 & 0.985 \\
unfiltered concrete & $-51 \pm 4$ & 16 & 0.983 \\
pH 12 buffer & $-49 \pm 7$ & 11 & 0.964 \\
total combined data & $-53 \pm 3$ & 46 & 0.977 \\
$a_{n}$ : number of analyzed data points. & & \\
\hline
\end{tabular}

obtained for all regressions. Carbon isotopic fractionation ranged from $-49 \pm 7 \%$ o to $-56 \pm 10 \%$ o for all experiments. The $95 \%$ confidence intervals of all $\varepsilon_{\mathrm{C}}$ values overlap. Consequently, an average $\varepsilon_{\mathrm{C}}$ value combining all data was determined to be $-53 \pm 3 \%$ o $\left(R^{2}=0.98\right)$. The apparent kinetic carbon isotope effect (AKIE) obtained was 1.056 \pm 0.003 (see SI for calculation details).

3.2. Field-Scale Experiments. The $\mathrm{pH}$ values of the water sampled from the two trenches remained constant $(11.6 \pm 0.3)$ throughout the 35-month sampling period. These results confirm the high buffering capacity of the recycled construction wastes. It should be noted that groundwater collected in all the aquifer monitoring wells shown in Figure S2 (SI), including the two wells located a few meters downgradient from the trenches, had neutral $\mathrm{pH}$ values, showing that alkaline conditions are restricted to the trenches. The results of additional lab experiments evaluating the interaction between alkaline water and the carbonate aquifer confirmed the high buffering capacity of the aquifer and the restriction of the alkaline conditions to the trenches (see SI for details). Table S1 (SI) shows the concentrations of cations in water collected on May 2008 from both trenches. The temperatures of the water collected from both trenches during the sampled period ranged between 14 and $17{ }^{\circ} \mathrm{C}$ (with mean values of $15.6 \pm 1.0{ }^{\circ} \mathrm{C}$ and $15.3 \pm 1.1$ ${ }^{\circ} \mathrm{C}$ for both trenches) according to seasonality, whereas the groundwater remained constant at a similar mean value of 15.4 $\pm 0.2{ }^{\circ} \mathrm{C}$ during the same studied period.

During the study period, the water table elevation in the trenches ranged from approximately 431 to $434 \mathrm{~m}$ above sea level (masl) (SI Figure S9). Water table fluctuations occurred in response to rainfall. A lag period of approximately 5-7 and 2030 days was observed between the precipitation events and the water level increases in the tank and pit trenches, respectively. The rapid recharge of the trenches can be seen after February 23rd 2011, when water of both trenches was removed for its management. Trench discharge after the high-intensity precipitation events proceeds according to Maillet's law. Under the four discharge conditions observed from May 2011 to March 2013 (SI Figure S9), the recession curves were used to calculate the average discharge flow rates for both trenches. The obtained average discharge flow rates were 0.18 $\pm 0.03 \mathrm{~m}^{3} \mathrm{~d}^{-1}$ and $0.23 \pm 0.06 \mathrm{~m}^{3} \mathrm{~d}^{-1}$ for the pit and tank trenches, respectively. The mean residence time of water in the trenches was calculated as the ratio of the effective trench volume to the average discharge flow rate. The obtained mean residence time was $513 \pm 86$ days and $730 \pm 190$ days for the pit and tank trenches, respectively. At the end of each of the four observed discharge cycles, discharge becomes zero and trench water remains at the minimum level (SI Figure S9). It should be noted that the first discharge cycle, with a duration of 90 days (see the period from June to October 2011 in SI Figure S9), is the only period without significant precipitation events and therefore corresponds to the maximum period without water entering the trenches.

In both trenches, significant variations in the CF concentration were observed over time (Figure 2). These fluctuations could be attributed not only to CF degradation but also to dilution effects due to the entry of rainwater after shortduration high-intensity precipitation events, to the leaching of contaminants retained in the unsaturated zone by rainwater after long-duration low-intensity precipitation events, to sorption and/or desorption processes of the contaminants on the mineral micropores, etc. Substantial enrichments in ${ }^{13} \mathrm{C}$ of $\mathrm{CF}$ over time occurred in both trenches (Figure 2), demonstrating $\mathrm{CF}$ transformation. In the two recharge periods, there was a general tendency of $\mathrm{CF} \delta^{13} \mathrm{C}$ values to increase in both trenches, with isotopic shifts of up to 20 and $28 \%$. Despite this general trend, certain $\mathrm{CF} \delta^{13} \mathrm{C}$ variability was observed due to the entry of nondegraded contaminant leaching from the subsoil after any precipitation event. Using the isotopic fractionation obtained from laboratory experiments $\left(\varepsilon_{\mathrm{C}}=-53 \pm 3 \%\right.$ ) , the extent of CF degradation in the trenches (D) was estimated assuming that the alkaline hydrolysis induced by construction wastes was the only 

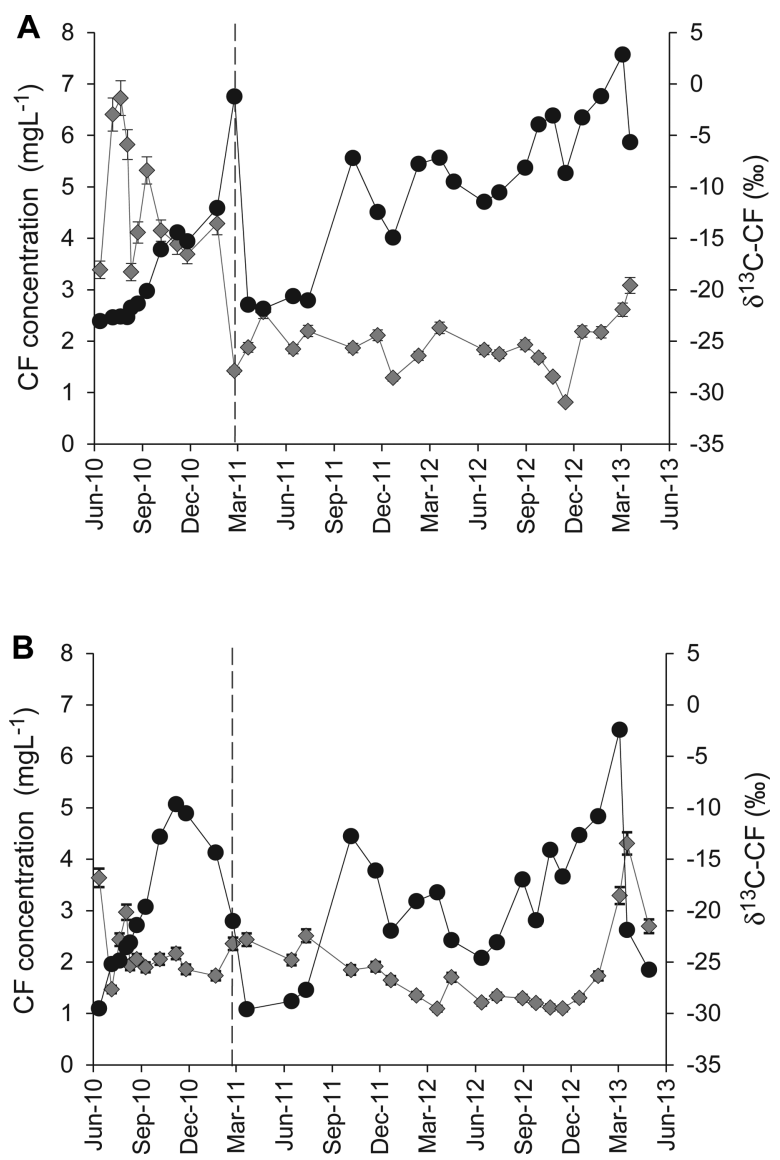

Figure 2. Variation over time of $\mathrm{CF}$ concentration (gray diamonds) and carbon isotope ratios $\left(\delta^{13} \mathrm{C}-\mathrm{CF}\right.$, black circles) in the (A) tank trench and (B) pit trench during the studied period. The error bars show the standard deviation for replicate measurements of the concentration and isotopic data. Dashed lines indicate the day when the trenches were completely emptied for the management of the contaminated water.

degradation fractionation process and fitted to the following expression derived from the Rayleigh distillation equation:

$$
D(\%)=\left[1-\left(\frac{\delta^{13} C_{t}+1000}{\delta^{13} C_{0}+1000}\right)^{1000 / \varepsilon_{C}}\right] \times 100
$$

where $\delta^{13} \mathrm{C}_{\mathrm{t}}$ and $\delta^{13} \mathrm{C}_{0}$ are the current and initial isotopic compositions (\%o) of $\mathrm{CF}$, respectively. The $\delta^{13} \mathrm{C}-\mathrm{CF}$ values measured in both trenches at the start of the study period $(-23.0 \pm 0.1 \%$ and $-29.5 \pm 0.2 \%$ o $)$, which correspond to the lightest values measured, were used as the initial isotopic compositions of CF for the tank and pit trenches, respectively. This assumes that these isotopic compositions represent the contaminant that has been subjected to the least degradation before reaching the trenches. The calculated percentage of $\mathrm{CF}$ degradation in both trenches is shown in Figure 3. The observed $\delta^{13} \mathrm{C}$ enrichments in the tank trench translate to maximum estimated extents of degradation of $34 \pm 5 \%$ and 39 $\pm 9 \%$ for the first and the second recharge periods, respectively. In the pit trench, the two enrichment periods translate to maximum estimated extents of degradation of $32 \pm 5 \%$ and 40 $\pm 3 \%$. The highest degrees of CF degradation occurred at the end of each observed discharge cycle, when discharge becomes
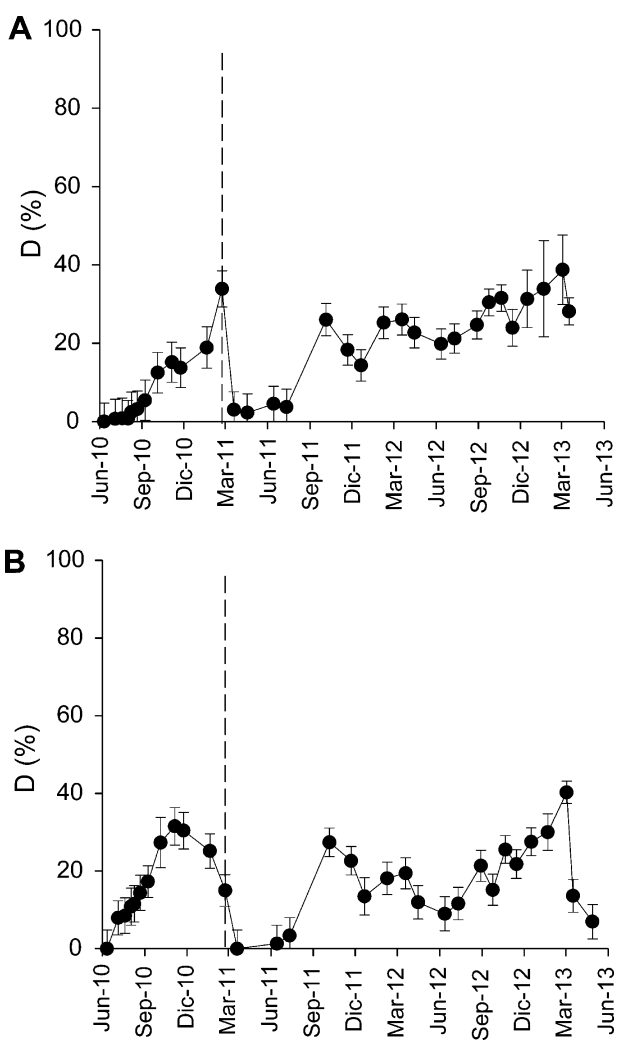

Figure 3. Estimation of the extent of chloroform degradation by alkaline hydrolysis induced by construction wastes in the (A) tank trench and the (B) pit trench using eq 1 . The uncertainty in the percentage of degradation was calculated by error propagation of the known total errors for $\delta^{13} \mathrm{C}-\mathrm{CF}$ measurements (the standard deviation of duplicated measurements) and $\varepsilon_{\mathrm{C}}$ estimation $( \pm 3 \%$ ) . Dashed lines indicate the day when the trenches were completely emptied for the management of the contaminated water.

zero and trench water was at the minimum level (Figure 3 and SI Figure S9).

The evolution over time of the concentration and carbon isotopic composition of the other major chlorinated volatile organic compounds present in the trench water (CT, perchloroethylene and trichloroethylene) is shown in the SI.

\section{DISCUSSION}

The laboratory experiments show that concrete particles immersed in water induced alkaline hydrolysis of CF, with 95\% consumption after $28 \mathrm{~d}$ (Figure 1). Degradation of CF was also observed in the other three alkaline treatments (chemical buffer, filtered cement and filtered concrete solutions), with half-lives below 15 days (Table 1). Aside from CF, no other chlorinated volatile compounds were detected by GC-MS in scan mode. This result supports the $\mathrm{E} 1_{\mathrm{CB}}$ degradation mechanism of $\mathrm{CF}$ reported by Hine, ${ }^{16}$ for which the final stable products were carbon monoxide (CO), formate $\left(\mathrm{HCO}_{2}{ }^{-}\right)$, and chloride $\left(\mathrm{Cl}^{-}\right)$. Furthermore, excellent chlorine balances were achieved in the filtered experiments, indicating that CF was degraded without accumulation of chlorinated intermediates (SI Figure S6). Nevertheless, no special attempts were made to identify other potential products of $\mathrm{CF}$ degradation. In the experiments with concrete particles, dissimilar chlorine balances were achieved in the two duplicates (set A and set B), reflecting the variability in chloride leaching due to the heterogeneity of the concrete particles. This 
heterogeneity could also be responsible for the poorer linear correlation between the CF concentration data and time and for the slightly lower degradation rate observed in the experiment with concrete particles compared to the filtered concrete experiment (Table 1 and SI Figure S4). Further research on the solid phase is required to confirm this assumption. The pseudo-first-order rate constants and half-lives obtained in this study of the hydrolysis of CF at room temperature are comparable to those calculated from the published values of Jeffers et al. ${ }^{22}$ and Fells and MoelwynHughes ${ }^{25}$ for $\mathrm{pH}$ values of 12 and 13 and a temperature range between 20 and $25{ }^{\circ} \mathrm{C}$ (Table 1 ).

The lab-scale mean carbon isotopic fractionation associated with alkaline hydrolysis of CF was $-53 \pm 3 \%$ (Table 2). To our knowledge, carbon isotopic fractionations associated with any abiotic CF degradation process have not been determined to date. The AKIE obtained at the lab-scale experiments (1.056 $\pm 0.003)$ is consistent with the theoretical maximum carbon primary $\mathrm{KIE}$ for the $\mathrm{C}-\mathrm{Cl}$ bond breakage (Streitwieser semiclassical upper limit of 1.057, Huskey ${ }^{42}$ ). The good correspondence between the theoretical KIE and the measured $\mathrm{AKIE}$ is consistent with an $\mathrm{E} 1_{\mathrm{CB}}$ mechanism for $\mathrm{CF}$ alkaline hydrolysis where the $\mathrm{C}-\mathrm{Cl}$ bond breakage is the rate determining step and, moreover, indicates that this type of abiotic reaction is not influenced by rate-limiting factors or masking effects due to mass transfer processes.

It is worth noting that microbial reductive dechlorination of CF by a Dehalobacter-containing culture resulted in a $\varepsilon_{\mathrm{C}}$ of $-27.5 \pm 0.9 \%{ }^{43}$, which represents the only documented CF $\varepsilon_{\mathrm{C}}$ value until now. Therefore, the difference between the carbon fractionation associated with CF abiotic alkaline hydrolysis and that associated with CF anaerobic respiration might potentially be used to distinguish abiotic from biotic degradation processes at contaminated sites.

The large carbon isotopic fractionation observed in the experiments implies a great potential for the use of $\delta^{13} \mathrm{C}$ values for in situ monitoring of the degree of degradation of CF by alkaline hydrolysis. Even minor extents of degradation will result in significant carbon isotope shifts that can easily be detected by CSIA. For example, considering a carbon fractionation of $-53 \pm 3 \%$, a $5 \%$ degradation will involve a change in $\delta^{13} \mathrm{C}$ values of $+2.7 \pm 0.1 \%$, which is significantly larger than the analytical uncertainty of $\pm 0.5 \%$.

The real concrete-based construction wastes used in the field-scale experiments maintained a constant $\mathrm{pH}$ of $11.6 \pm 0.3$ in pore water during the entire study period (35 months), confirming the longevity of concrete-based aggregates for inducing alkaline conditions. The results of the long-term fieldscale pilot interception trenches, with significant ${ }^{13} \mathrm{C}$ enrichments, confirmed the capability of concrete-based construction wastes to induce alkaline hydrolysis of CF. Although the $\mathrm{pH}$ achieved by the used construction wastes in the field-scale experiments was slightly lower than the $\mathrm{pH}$ range studied in the lab-scale experiments, the independence observed between $\mathrm{pH}$ (from 12.0 to 12.7 ) and $\varepsilon_{\mathrm{C}}$ should allow us to estimate the extent of induced alkaline hydrolysis of $\mathrm{CF}$ in the field-scale experiments through the laboratory-obtained $\varepsilon_{\mathrm{C}}(-53 \pm 3 \%$ o). However, further experiments at lower $\mathrm{pH}$ values should be done to ensure this assumption. A maximum CF degradation percentage between 32 and $40 \%$ was achieved in both trenches during the two studied periods (Figure 3). The efficiency in CF degradation depends on the precipitation regime. Any precipitation event could result in the entry of nondegraded contaminant leaching from the subsoil that would dilute the degradation effect. The alkaline conditions induced by the recycled concrete-based construction wastes were restricted to the trenches and did not negatively affect the natural attenuation processes of chlorinated compounds in the aquifer below the trenches. ${ }^{40}$ Actually, a concentration reduction of $\mathrm{CF}$ might be a key strategy for bioremediation purposes ${ }^{44}$ because $\mathrm{CF}$ is a potent inhibitor of several microbial processes, such as methanogenesis or reductive dechlorination of chlorinated ethenes, the other major group of pollutants at the site. ${ }^{45}$ Moreover, temperature has a substantial effect on the abiotic degradation rates of chlorinated compounds. The half-lives recalculated from published kinetic data at a typical groundwater temperature of $10{ }^{\circ} \mathrm{C}$ are approximately 15 times higher than those for $25{ }^{\circ} \mathrm{C}$ (Table 1). At lower groundwater temperatures, for example $5{ }^{\circ} \mathrm{C}$, alkaline hydrolysis of $\mathrm{CF}$ at $\mathrm{pH}$ 12 would yield a half-life of approximately 500 days (Table 1 ). Therefore, temperature must be accounted for to predict the effectiveness of remediation strategies based on alkaline hydrolysis in the field. In the present field-scale experiments, the temperature remained approximately $15{ }^{\circ} \mathrm{C}$ in both trenches, which was very similar to the underlying groundwater. The half-life calculated from the published values of Fells and Moelwyn-Hughes ${ }^{25}$ for $\mathrm{pH} 11.6$ and $15^{\circ} \mathrm{C}$ was 179 days, which is a promising result for the potential full implementation of this remediation approach at the site. For the mean calculated residence time of water in the trenches $(513 \pm 86$ and $730 \pm$ 190 days), a maximum theoretical percentage of degradation of approximately $90 \%$ would be achieved if there was no entry of new nondegraded contaminant leaching from the unsaturated zone by rainwater. Taking into account the maximum period without water entry into the trenches, and thus nondegraded contaminant entry (90 days, from June to October 2011, SI Figure S9), a maximum theoretical percentage of CF degradation of $30 \%$ can be estimated for both trenches, which is in agreement with the isotopic results. Therefore, the actual efficiency of the treatment depends on the precipitation regime and can easily be estimated by monitoring the $\mathrm{CF}$ isotopic composition.

Taking this into account, improvements in the design of the interception trenches can be proposed to increase the residence time in the system, such as the enlargement of the dimensions of the trenches or increasing the $\mathrm{pH}$ by choosing different concrete-based materials. The $\mathrm{pH}$ of leaching solutions of recycled concrete aggregates depends on the degree of carbonation. A study from Engelsen et al. ${ }^{46}$ on the alkaline capacity of several recycled concrete aggregates, including waste construction materials, found not only similar $\mathrm{pH}$ ranges as the ones observed in this study but also that a higher $\mathrm{pH}$ of 12.6 was reached with concrete material recycled from a highway pavement constructed in the beginning of 1980s. This material would result in a CF half-life of 18 days, which would translate into a maximum extent of degradation of $97 \%$ in the trenches during periods without the entrance of nondegraded contaminant. Monitoring of the isotopic composition would be required to estimate the actual efficiency of the treatment.

Overall, these results indicate that alkaline hydrolysis induced by concrete-based construction wastes seems to represent a potential alternative remediation strategy for CF-contaminated recharge water before the water reaches fractured aquifers. Furthermore, it is proposed that construction wastes could be implemented as a permeable reactive barrier (PRB) system to degrade CF by alkaline hydrolysis in combination with ISCO, 
which would be able to remove the rest of the accompanying pollutants (usually perchloroethylene, trichloroethylene and cis-1,2-dichloroethylene). Thus, the combination of the two methods, neither of which alone could achieve the degradation of all the compounds, might achieve an efficient decontamination of the groundwater. The usefulness of carbon isotope analyses to evaluate the effectiveness of these types of remediation approaches is also verified in this study. Recycling and reusing construction wastes would furthermore result in environmental and economic benefits.

\section{ASSOCIATED CONTENT}

\section{S Supporting Information}

Experimental details, the approach for the quantification of isotopic fractionation and the kinetics of alkaline hydrolysis, the field-scale pilot experiment layout with compound concentrations and piezometric information, a schematic representation of the proposed hydrogeological performance of the trenches, the $\ln \left(\mathrm{C} / \mathrm{C}_{0}\right)$ vs time plot for the lab-scale experiments, the correlation between the $\mathrm{OH}^{-}$concentrations and pseudo-first-order rate constants of the lab experiments, the chlorine mass balance in selected lab experiments, plots for the calculation of $\varepsilon_{\mathrm{C}}$ during $\mathrm{CF}$ degradation by alkaline hydrolysis for selected lab experiments, additional lab experiments of alkaline water and carbonated aquifer interaction, the evolution of the water table elevation over time in the fieldscale experiments, a discussion of cation release, the evolution of the concentration and carbon isotopic composition of other chlorinated volatile organic compounds over time in the fieldscale experiments and a discussion of $\mathrm{CT}$ behavior. This information is available free of charge via the Internet at http:// pubs.acs.org/.

\section{AUTHOR INFORMATION}

\section{Corresponding Author}

*Phone: +34 9340337 73; fax: +34 9340213 40; e-mail: clara. torrento@ub.edu.

\section{Notes}

The authors declare no competing financial interest.

\section{ACKNOWLEDGMENTS}

This work has been carried out with the economical support of the projects CGL2011-29975-C04-01 from the Spanish Government and 2009SGR-00103 from the Catalan Government and a Marie Curie Career Integration Grant in the framework of the IMOTEC-BOX project (PCIG9-GA-2011293808) within the European Union 7th Framework Programme. We want to thank Dr. Albert Folch from the "Universitat Politècnica de Catalunya" for helping in the interpretation of hydrogeological data; Arnau Follia, Ignasi Hernández, Oriol Diaz, Pol Pla, Adriana Rossi, and Diana Rodriguez-Fernandez for helping with the field-scale experiment; and the "Centres Cientifics i Tecnològics" of the "Universitat de Barcelona" for their services. The authors would like to thank J.A. Domènech and J. Bartoll ("Agència de Residus de Catalunya") for their support. We are grateful to Dr. Jennifer A. Field and three anonymous reviewers for the beneficial comments that increased the quality of the manuscript.

\section{REFERENCES}

(1) Carter, J. M.; Lapham, W. W.; Zogorski, J. S. Occurrence of volatile organic compounds in aquifers of the United States. J. Am. Water Resour. Assoc. 2008, 44 (2), 399-416.

(2) ATSDR. Priority list of hazardous substances. Agency for Toxic Substances and Disease Registry Website. , http://www.atsdr.cdc.gov/ $\mathrm{spl} /$

(3) Penny, C.; Vuilleumier, S.; Bringel, F. Microbial degradation of tetrachloromethane: Mechanisms and perspectives for bioremediation. FEMS Microbiol. Ecol. 2010, 74, 257-275.

(4) Cappelletti, M.; Frascari, D.; Zannoni, D.; Fedi, S. Microbial degradation of chloroform. Appl. Microbiol. Biot. 2012, 96, 1395-1409.

(5) Grostern, A.; Duhamel, M.; Dworatzek, S.; Edwards, E. Chloroform respiration to dichloromethane by a Dehalobacter population. Environ. Microbiol. 2010, 12, 1053-1060.

(6) Lee, M.; Low, A.; Zemb, O.; Koenig, J.; Michaelsen, A.; Manefield, M. Complete chloroform dechlorination by organochlorine respiration and fermentation. Environ. Microbiol. 2012, 14 (4), 883894.

(7) Shan, H.; Kurtz, H. D., Jr; Freedman, D. L. Evaluation of strategies for anaerobic bioremediation of high concentrations of halomethanes. Water Res. 2010, 44, 1317-1328.

(8) Huling, S. G.; Pivetz, B. E. In Situ Chemical Oxidation-Engineering Issue, EPA/600/R-06/072; U.S. Environmental Protection Agency Office of Research and Development, National Risk Management Research Laboratory: Cincinnati, OH, 2006; http://www.epa.gov/ $\mathrm{ada} / \mathrm{gw} / \mathrm{pdfs} /$ insituchemicaloxidation_engineering_issue.pdf

(9) Su, T.-L.; Christodoulatos, C. Destruction of nitrocellulose using alkaline hydrolysis. In Proceedings of the Tri-Service Environmental Technology Workshop; Hershey, PA, 1996; pp 337-343.

(10) Emmrich, M. Kinetics of the alkaline hydrolysis of important nitroaromatic co-contaminants of 2,4,6-trinitrotoluene in highly contaminated soils. Environ. Sci. Technol. 2001, 35 (5), 874-877.

(11) Hwang, S.; Felt, D. R.; Bouwer, E. J.; Brooks, M. C.; Larson, S. L.; Davis, J. L. Remediation of RDX-contaminated water using alkaline hydrolysis. J. Environ. Eng. 2006, 132 (2), 256-262.

(12) Hwang, S.; Ruff, T. J.; Bouwer, E. J.; Larson, S. L.; Davis, J. L. Applicability of alkaline hydrolysis for remediation of TNTcontaminated water. Water Res. 2005, 39, 4503-4511.

(13) Karakaya, P.; Sidhoum, M.; Christodoulatos, C.; Nicolich, S.; Balas, W. Aqueous solubility and alkaline hydrolysis of the novel high explosive hexanitrohexaazaisowurtzitane (CL-20). J. Hazard Mater. 2005, 120, 183-191.

(14) NorthPestClean Demonstration of in Situ Alkaline Hydrolysis As a New Technology for Remediation of Pesticide Contaminated Soil and Groundwater, Technical pamphlet of the LIFE09 ENV/DK/000368 projec, 2013.

(15) Church, C. D.; Pankow, J. F.; Tratnyek, P. G. Hydrolysis of tertbutyl formate: Kinetics, products, and implications for the environmental impact of methyl tert-butyl ether. Environ. Toxicol. Chem. 1999, 18 (12), 2789-2796.

(16) Sarathy, V.; Salter, A. J.; Nurmi, J. T.; O’Brien Johnson, G.; Johnson, R. L.; Tratnyek, P. G. Degradation of 1,2,3-trichloropropane (TCP): Hydrolysis, elimination, and reduction by iron and zinc. Environ. Sci. Technol. 2010, 44 (2), 787-93.

(17) Bondgaard, M.; Hvidberg, B.; Melvej, A.; Ruegg, K.; Ernst, L.; Damgaard, T.; Fredborg, H.; Rügge, K.; Nissen, L.; Jorgensen, T. H.; Bennedsen, L.; Mackinnon, L.; Durant, N.; Thomas, M.; Petrovskis, E. "NorthPestClean"-A large-scale demonstration project of in situ alkaline hydrolysis. In Book of Abstracts of the 12th International UFZDeltares Conference on Groundwater-Soil-Systems and Water Resource Management, Barcelona, 2013; pp 139

(18) Schwarzenbach, R. P., Gschwend, P. M., Imboden, D. M. Environmental Organic Chemistry, 2nd ed.; John Wiley \& Sons: Hoboken, NJ, 2003.

(19) Bruckner, R. Advanced Organic Chemistry: Reaction Mechanisms; Academic Press: New York, NY, 2002. 
(20) Hine, J. Carbon dichloride as an intermediate in the basic hydrolysis of chloroform. A mechanism for substitution reactions at a saturated carbon atom. J. Am. Chem. Soc. 1950, 72, 2438-2445.

(21) Mabey, W.; Mill, T. Critical review of hydrolysis of organic compounds in water under environmental conditions. J. Phys. Chem. Ref. Data 1978, 7 (2), 383-415.

(22) Jeffers, P. M.; Ward, L. M.; Woytowltch, L. M.; Wolfe, N. L. Homogeneous hydrolysis rate constants for selected chlorinated methanes, ethanes, ethenes, and propanes. Environ. Sci. Technol. 1989, 23 (8), 965-969.

(23) Vogel, T. M. Natural bioremediation of chlorinated solvents. In Handbook of bioremediation; Norris, R. D., Hinchee, R. E., Brown, R. McCarty, P. L., Semprini, L., Wilson, J. T., Kampbell, D. H., Reinhard, M., Bouwer, E. J., Borden, R. C., Vogel, T. M., Thomas, J. M., Ward, C. H., Eds.; Lewis Publishers: Boca Raton, FL, 1994; pp 201-222.

(24) Miyamoto, K.; Urano, K. Reaction rates and intermediates of chlorinated organic compounds in water and soil. Chemosphere 1996, 32 (12), 2399-2408.

(25) Fells, I.; Moelwyn-Hughes, E. A. The kinetics of the hydrolysis of the chlorinated methanes. J. Chem. Soc. 1959, 398-409.

(26) Valiev, M.; Garrett, B. C.; Tsai, M. -K.; Kowalski, K.; Kathmann, S. M.; Schenter, G. K.; Dupuis, M. Hybrid approach for free energy calculations with high-level methods: Application to the $\mathrm{SN}_{2}$ reaction of $\mathrm{CHCl}_{3}$ and $\mathrm{OH}^{-}$in water. J. Chem. Phys. 2007, 127, 051102-1-4.

(27) Amonette, J. E.; Jeffers, P. M.; Qafoku, O.; Russell, C. K.; Humphrys, D. R.; Wietsma, T. W.; Truex, M. J. Abiotic Degradation Rates for Carbon Tetrachloride and Chloroform: Progress in FY 2010; PNNL-20044, Pacific Northwest National Laboratory: Richland, WA, 2010; http://www.pnl.gov/main/publications/external/technical_ reports/PNNL-20044.pdf

(28) Golab, A. N.; Peterson, M. A.; Indraratna, B. Selection of potential reactive materials for a permeable reactive barrier for remediating acidic groundwater in acid sulphate soil terrains. Q. J. Eng. Geol. Hydrogeol. 2006, 39, 209-223.

(29) Indraratna, B.; Regmi, G.; Nghiem, L. D.; Golab, A. Performance of a PRB for the remediation of acidic groundwater in acid sulfate soil terrain. J. Geotech. Geoenviron. Eng. 2010, 136 (7), 897-907.

(30) Regmi, G.; Indraratna, B.; Nghiem, L. D.; Guruprasad, A. N.; Guruprasad, B. Treatment of acid groundwater in acid sulphate soil terrain using recycled concrete: Column experiments. J. Environ. Eng. 2011, 137 (6), 433-443.

(31) Hwang, I.; Batchelor, B. Reductive dechlorination of tetrachloroethylene by $\mathrm{Fe}(\mathrm{II})$ in cement slurries. Environ. Sci. Technol. 2000, 34 (23), 5017-5022.

(32) Hwang, I.; Batchelor, B. Reductive dechlorination of chlorinated methanes in cement slurries containing Fe(II). Chemosphere 2002, 48, 1019-1027.

(33) Hwang, I.; Park, H.-J.; Kang, W.-H.; Park, J.-Y. Reactivity of $\mathrm{Fe}(\mathrm{II}) /$ cement systems in dechlorinating chlorinated ethylenes. $J$. Hazard. Mater. 2005, B118, 103-111.

(34) Meckenstock, R. U.; Barbara Morasch, B.; Griebler, C.; Richnow, H. H. Stable isotope fractionation analysis as a tool to monitor biodegradation in contaminated aquifers. J. Contam. Hydrol. 2004, 75, 215-255.

(35) Harrington, R. R.; Poulson, S. R.; Drever, J. I.; Colberg, P. J. S.; Kelly, E. F. Carbon isotope systematics of monoaromatic hydrocarbons: Vaporization and adsorption experiments. Org. Geochem. 1999, 30, 765-775.

(36) Poulson, S. R.; Drever, J. I. Stable isotope (C, Cl, and H) fractionation during vaporization of trichloroethylene. Environ. Sci. Technol. 1999, 33 (20), 3689-3694.

(37) Slater, G. F.; Ahad, J. M. E.; Sherwood Lollar, B.; Allen-King, R. M.; Sleep, B. E. Carbon isotope effects resulting from equilibrium sorption of dissolved VOCs. Anal. Chem. 2000, 72 (22), 5669-5672.

(38) Schüth, C.; Taubald, H.; Bolaño, N.; Maciejczyk, K. Carbon and hydrogen isotope effects during sorption of organic contaminants on carbonaceous materials. J. Contam. Hydrol. 2003, 64, 269-281.
(39) Wang, Y.; Huang, Y. S. Hydrogen isotopic fractionation of petroleum hydrocarbons during vaporization: Implications for assessing artificial and natural remediation of petroleum contamination. Appl. Geochem. 2003, 18 (10), 1641-1651.

(40) Palau, J.; Marchesi, M.; Chambon, J. C. C.; Aravena, R.; Canals, À.; Binning, P. J.; Bjerg, P. L.; Otero, N.; Soler, A. Multi-isotope (carbon and chlorine) analysis for fingerprinting and site characterization at a fractured bedrock aquifer contaminated by chlorinated ethenes. Sci. Total Environ. 2014, 475, 61-70.

(41) Parkhurst, D. L. User'S Guide to PHREEQC-A Computer Program for Speciation, Reaction-Path, Advective-Transport, And Inverse Geochemical Calculations; U.S. Geological Survey Water-Resources Investigations Report, 1995; 95-4227.

(42) Huskey, W. P. Enzyme mechanism from isotope effects. In Enzyme Mechanism from Isotope Effects; Cook, P. F., Ed.; CRC Press: Boca Raton, FL, 1991; pp 37-72.

(43) Chan, C. C. H.; Mundle, S. O. C.; Eckert, T.; Liang, X.; Tang, S.; Lacrampe-Couloume, G.; Edwards, E. A.; Sherwood-Lollar, B. Large carbon isotope fractionation during biodegradation of chloroform by Dehalobacter cultures. Environ. Sci. Technol. 2012, 46, 1015410160.

(44) Koenig, J. C.; Lee, M. J.; Manefield, M. Successful microcosm demonstration of a strategy for biodegradation of a mixture of carbon tetrachloride and perchloroethene harnessing sulfate reducing and dehalorespiring bacteria. J. Hazard. Mater. 2012, 219-220, 169-175.

(45) Maymó-Gatell, X.; Nijenhuis, I.; Zinder, S. H. Reductive dechlorination of cis-1,2-dichloroethene and vinyl chloride by Dehalococcoides ethenogenes. Environ. Sci. Technol. 2001, 35 (3), 516521.

(46) Engelsen, C. J.; van der Sloot, H. A.; Wibetoe, G.; Petkovic, G.; Stoltenberg-Hansson, E.; Lund, W. Release of major elements from recycled concrete aggregates and geochemical modeling. Cem. Concr. Res. 2009, 39, 446-459. 